\title{
The Construction of EAP Textbooks in Chinese Context from the Perspective of Eco-education Theory
}

\author{
Ning Dali ${ }^{1}$ \\ ${ }^{1}$ Guangdong University of Foreign Studies, China \\ Correspondence: Ning Dali, Guangdong University of Foreign Studies, China. E-mail: \\ 200411216@oamail.gdufs.edu.cn
}

Received: March 15, 2017 Accepted: April 25, 2017 Online Published: April 27, 2017

doi: 10.5539/elt.v10n5p214 URL: http://doi.org/10.5539/elt.v10n5p214

\begin{abstract}
The increase of international exchange in education triggers strong demand for learning English language skills in various academic disciplines among Chinese students, which brings up a wide implementation of EAP (English for academic purposes) learning in universities in China. However, the teaching and learning result do not seem to be as satisfactory. A key factor to the disappointing situation is the lack of suitable textbooks. Currently, most of the few domestically designed EAP textbooks only focus on the reading and writing and cannot meet the learners' needs of overall (listening, speaking, reading and writing) development. The adoption of textbooks designed abroad was found unable to cater to the needs and language proficiency of the learners in China. There is an urgent need of constructing localized textbook for EAP learning in Chinese context. Previous frameworks on textbook design are mainly based on linguistic theories, which though offer theoretical support of language study from the perspective of learning subjects did not pay attention to the interconnection of factors within the learning environment. This paper proposes the application of eco-education theory to the design of a localized EAP textbook. It stresses the importance of the interrelations between textbook, editor, researcher, teacher and student during the process of designing a localized textbook so as to promote a healthy and sustainable development of EAP learning in Chinese context.
\end{abstract}

Keywords: EAP, textbook construction, eco-education theory, localization

\section{Urgent Need VS. Low Efficiency of EAP Learning in China}

\subsection{Rising demand of EAP Learning in China}

As globalization furthers, international exchanges extend to every aspect of human life. College students in China are exposed to vast amount of academic resources: English lectures, talks (i.e. TED), essays, books, and meetings, etc. A great number of college students in China, in their senior years, are required to take courses of their specialties in English. This brings a rising demand for learning basic conventions of language knowledge in academic context. EAP, a course that aims to equip learners with general skills in different academic disciplines is experiencing rapid growth in China. According to a survey conducted by Cai Jigang in $2012,80 \%$ of the freshmen in Chinese colleges regarded English as 'a tool to understand and exchange information of a specialty, means to enhance the international communicative ability in a specialized field.' Over $60 \%$ of them wanted to 'enhance the ability of learning the specialty by using English as a tool (for example, ability to read and search for the literatures they need for their major study, ability to understand a lecture of a particular field and the ability to interpret and demonstrate the academic results, etc)' (Cai, 2014). As is shown from the interview, the skills students want to obtain from EAP course include strategies to understand academic lectures and speeches (including skills of taking notes, asking and answering questions and writing summary); give presentations and exchange opinions in discussions using standard academic language expressions; understand essays (general knowledge) of different disciplines (identify structures of texts of different genres, recognize author's stance, think critically and write summary, etc); and to command skills for simple academic writing(write definitions, topic sentences, describe diagrams, argue for viewpoints, compare and contrast items, etc). The nationwide implementation of EAP was the result of such strong demand among Chinese college students.

EAP is divided into EGAP (English for general purposes) and ESAP (English for academic purposes) (Jordan, 1997). The former aims to teach the core skills, tasks and language needed for general academic disciplines while the latter focuses on professional English of a particular specialty. To the freshmen who just finished their 
high school study where English classes focused on basic grammar and simple vocabulary for daily communication, EGAP is the course they need to take first. EGAP is a bridging course that develops the students' integrated skills for general academic disciplines and helping them to understand the language features in different academic contexts and paves the way for future learning of EGSP or lessons of their specialty taught in English.

In the fall of 2013, Shanghai launched an innovation on College English teaching. EAP was designed as a core course to help a smooth and gradual transition from General English to Academic English. As the innovation furthers, EAP soon became a compulsory course in many universities in China.

\subsection{Problems during Implementation}

Though EAP has been widely implemented in China, the teaching and learning do not turn out to be smooth. The first problem is the lack of suitable textbook. Currently, most of the EAP textbooks available in domestic market (the Reading Course of English Science and Technology, Yang Min, Yang Xiufen, 2007; Scientific English, Qin Dihui, 2003; EST Reading, Han Mengqi, 200; Academic English for Social Sciences, Ji Peiying, Zhang Yin,2012; English Writing for Academic Purposes, Yuli, Liangjie, Chen Yonggang, 2015; New Century College English: Listening and Notetaking Skills, Yang Huizhong, Wang Yuewu, 2015; Comprehensive courses for General Academic English, Yang Yuanyuan, 2016, etc) focus on reading and writing only. Few offer materials for listening and speaking exercises. And there are even fewer to develop the learners' competence in all (listening, speaking, reading and writing) aspects. To satisfy the learners' need for overall enhancement of English in academic disciplines, some universities in China adopted textbooks that integrate the four kinds of competence designed in English native speaking countries despite of the high cost. Among these imported books, the most influential is Oxford EAP-A course in English for Academic Purposes, published by Oxford University Press, one that enjoys a long history of developing EAP textbooks. It is a book designed with authentic academic texts with multi-model materials (words, pictures, audio and vedio clips, etc). There are logical and consistent organization of activities within each unit to satisfy learning the four skills (i.e., listening, speaking, reading, and writing) by including diverse language activities related to the objectives. However, the learning results and feedback do not turn out to be as satisfactory. Take my university (one that enjoys a good reputation of foreign language learning in South China) for example, there are over 4000 freshmen taking this course every year. Quite a few students cannot produce qualified assignments as requested and few(less than 5) in one class (over 40 students per class) get an "excellent" in either mid-term or final examination. Moreover, the teaching feedback was frustrating. Compared with the teaching assessment (evaluated by students to every teacher at the end of each semester) for general English, the average assessment score for EAP was more than 1 point lower (the gap between two teachers was less than 0.1 in the whole institute). According to the interview with the students, the reasons that they are not keen to the learning of EAP are as follows: unlike general English, which is simple and all topics of which are related to daily life, EAP seems to be 'boring' and difficult; the vocabulary(the average receptive vocabulary of a Chinese high school graduate is about 4,000 , much less in productive vocabulary) and sentence structure in the reading and writing materials are far beyond their present language proficiency; some of the listening materials concerning topics that are related to science (such as photosynthesis, Linnaeus's classification) are hard to understand for second language learners with limited vocabulary; units that introduce the skills of writing academic research paper kills their interest of learning this course for they won't have the chance to write one in the recent two years (students in China are not required to write academic papers in their first two years' study and some even won't write one until they prepare for their graduate thesis) ; some follow up exercises are either too simple or too difficult for them; some teachers themselves are not familiar enough with this course and materials.

As is shown from the interview results, one of the most influential factors for EAP learning and teaching is the textbook. Materials that do not fit well the needs and language proficiency of the learners may hugely weaken the learning interest and results. To effectively satisfy the learning needs, there is the urgent need of more researches and practice on the development EAP textbook especially designed for learners in Chinese context.

\section{EAP Textbook Construction in China}

In contrast to the growing demand of learning English for academic purposes, the supply of EAP textbooks in Chinese market is lagged far behind. Most of the textbooks that aim to develop learners' academic competence focus on the field of science and technology (as is shown in the above section). More importantly, they only address skills in reading and writing, which fails to meet the learners' need of obtaining skills in real communicative context.

A solution to solve the problem of short supply is to adopt textbooks designed by experienced publishers abroad 
to develop students' overall language competence in different academic disciplines. Generally, these textbooks are carefully designed with clear objectives, diversified materials, and good combination of knowledge and language points (Shu, 2014). However, it is discovered during implementation that the materials are not especially designed for Chinese students and the choice of vocabulary, the sentence structures, design of exercises and study expectations, etc, do not meet the language proficiency of the students in China. According to the Comprehensible Input Hypothesis, when the input is too much more difficult than what the learner's present proficiency is, the learner will lose confidence as well as interest in learning. Moreover, T.Yakhontova (2001) discovers that learner's comprehension of new materials is heavily influenced by the beliefs and values of his living environment, which indicates learners from non-English speaking countries may come across difficulties in adapting themselves to the textbooks designed by English-speaking countries due to the cultural differences. The importance of the localization of the textbook cannot be ignored when put in practice.

Research on EAP textbook construction is still underdeveloped in China. Sun Yunbo and Feng Jie (2014) calculated the researches that have been published in the previous thirty years on the platform of CNKI (China National Knowledge Infrastructure), among which few papers on the study of EAP were found and most of the published ones were about EAP teasching, needs analysis and curriculum design. The few researches that were conducted on EAP textbooks fall into three categories: the introduction of research achievement abroad, assessment of the current textbooks by adopting influential frameworks abroad and guidelines and principles proposed by authoritative experts in the country. Though providing references for EAP textbook design in the country, these researches fail to form a systematic theoretical framework catering to Chinese context (Wang \& Zhao, 2006).

\section{The Main Frameworks for the Evaluation of EAP Textbooks in Previous Studies}

Researches on EAP textbook evaluation started from 1980s. The traditional way of textbook evaluation is to match the features of a textbook with a list worked out by some linguistic theories (i.e. system functional linguistics, cognitive linguistics and sociolinguistics, etc). The most widely adopted frameworks are Hutchinson and Waters (1987), Cunningsworth (1984), McDonough and Shaw (1993), Breen and Candlin (1987) etc.

Hutchinson and Waters (1987) proposed that textbook evaluation was a process of matching. First of all, the evaluators made a list of variables for the requirements of a textbook. Meanwhile, the features of the textbook were listed. This was followed by the matching job. Opinions from experts, would be combined with the investigation results (with teachers and students being interviewee) to check whether the textbook is in line with the variables.

Cunningsworth (1984) listed a detailed matching list for textbook selection and e valuation, including purposes, methodology, design, organization, language content, skills, topics, teaching pedagogy and teacher's book, etc. In this evaluation framework, language was the main focus. Many language forms and uses such as grammar, vocabulary, collocation, pronunciation and discourse analysis were included. It provided a very detailed list for textbook evaluation but meanwhile seemed not quite feasible because of so many variables.

The system proposed by McDonough and Shaw (1993) was made up of three parts: external evaluation, internal evaluation and comprehensive evaluation. External evaluation made a simple judgment on the outlook of the textbook, such as the front page, introduction and catalogue, etc so as to have a general knowledge of the target user, application environment, content arrangement, and the editor's viewpoint on language and teaching pedagogy. The internal evaluation aimed to check whether the internal factors of a textbook such as language skill, difficulty classification, order, oral and listening materials, etc, matched the variables listed for external evaluation. Comprehensive evaluation inspects the feasibility, and flexibility of the use of the textbook, etc. This evaluation system simplified the evaluating process and helped the evaluators to make a quick judgment. For example, if a textbook was found to be unsuitable for learners of a certain level, the teacher can easily made the decision of not using it within a short period of time. However, this system mainly evaluated the textbook from the teacher's or evaluator's perspective and concerned little about the learners.

Breen and Candlin (1987) proposed two stages for textbook evaluation. The first stage was to evaluate the use of textbook, for example, the purpose, content, requirement for learners and teaching, and the function of the textbook as teaching resource, etc. The second stage further analyzed whether the textbook was able to meet the demand and the interest of the learners; whether it suited the learners' learning habit and was in line with classroom teaching. Teachers and learners were encouraged to participate the in the evaluation. This evaluation system took learners as the center and advocated that learners and their learning partners achieve the learning objectives through cooperation.

Generally the previous practice to assess a textbook is to match the features of a textbook with the variables on a 
list worked out by researchers. These variables proposed in the frameworks are based on well accepted linguistic theories. For quite a long time, language was viewed as the major concern for the design of a textbook. Though the focus was later transferred to the learners, little attention was paid to the fact that factors such as learner, learning material, teacher, editor and researcher are equally important in the learning process as they coexist and interact with each other under the same learning environment. It is the interconnection between the factors that decides the construction and implementation of a textbook.

\section{EAP Textbook Construction based on Eco-Education Theory in Chinese Context}

\subsection{Eco-education Theory and EAP Textbook Construction}

The concept of "educational ecology" was firstly proposed by Lawrence Gremin in 1976 who attempted to analyze phenomenon and problems in education by applying theories and methods in the field of ecology. Lawrence (1976) believes that ecology brings new perception to the studies of education in that it highlights inter-relationship. Eco-education theory suggests that education is an ecosystem of a dynamic interplay of multiple factors, including learning environment (such as society, the political, economic, and cultural factors, school, classroom, family, community, and individual, etc) and the learning subjects (such as teachers and students, e.g.).

The introduction of ecological principles to language studies transfers the public attention from purely linguistic perspectives to the interrelation between a certain language and its environment. For years constructivism has been referred to as the guiding theory for language learning. It proposes that language knowledge is not acquired through the learning from teachers but through cooperation with help from others (i.e. teachers and peer learners) Eco-education theory advances constructivism for language study in that the former offers a detailed description of the meaning construction between and within learning subjects (such as learners and teachers), while the latter emphasizes the connection and balance between factors in the whole learning environment (teachers, learners, resources, outside classroom factors, etc).

EAP learning, when viewed from eco-education theory, is an ecosystem made up of factors, such as textbook, teacher, learner, editor and researcher, etc, each somehow restricts and meanwhile relies on the others for survival and development. The production of EAP textbook, therefore, is an interactive process of all factors involved in the system. Ignorance of any factor or the interrelations among them may lead to an imbalanced development of the learning environment and thereafter a dissatisfactory learning result.

\subsection{The Application of Eco-education Theory to EAP Textbook Construction}

According to eco-education theory, the design of EAP textbook cannot be successful if it fails to maintain a balanced operation of the ecological factors in the learning environment. Hence, the EAP textbook construction is the design of every ecological factor that helps the successful implementation and sustainable development of it. The following part of this paper focuses on the consideration of the manageable ecological factors so as to maintain a balanced development of EAP learning environment.

\subsubsection{Editors, Teachers and Researchers}

Needs analysis is the initial step for langue curriculum design and implementation to foreign language teaching, (Shu, 2004). This is the step that decides 'what to teach and how'. Needs analysis includes the investigation of learning objectives, background, curriculum requirement, academic tasks, the collection of authoritative learning materials, the observation of lectures and understanding of the language features and behaviors, etc (Hyland, 2006). Teachers play the important role of connecting textbook and students. Experienced teachers are ideal editors for textbook design and evaluation since they have a profound understanding on course design, classroom management, use of materials and the learning situation of the students. Students are the major consumer of the textbook, the center of learning. Their participation into the evaluation of the textbook brings a clear understanding of their needs to the editors and teachers, which as a result, enhances the quality and adaptability of the textbook.

Textbook research provides theoretical guidance and data support for textbook construction and ensures unity and coherence of curriculum design. According to Tomlinson (2003), textbook design that is based on research helps the editors to write effective and efficient materials and to interpret the principles and theories they behold to language teaching and learning. EAP textbook editors are expected to be equipped with the latest research findings to work out criteria which not only reflects the latest development of this field but meet the latest need of the consumers and apply them to the selected materials and exercise designs. Therefore, EAP textbook that works best might be designed by the joint effort of editors, teachers and researchers with students' feedback being part of the evaluation. The ideal editors, of course, are experienced teachers who conduct researches in this 
field.

\subsubsection{Teachers and the Learners}

Teachers and the learners are the implementers of the textbook and main evaluators of its adaptability. Textbook is the medium between teachers and learners, with teachers controlling the language input and output process. In China, EAP is not only a new course to students but also a new trial to most of the teachers. Teachers who have been accustomed to teaching general English (the major role of which is to enhance the leaner's' competence of using English language for daily communicative purposes by using more advanced materials than those in high schools) find it rather difficult to adapt themselves to the use of academic materials. Many of them have not been educated with such a systematic introduction of academic skills themselves. It is essential that teachers who firstly take this course be given training about the theoretical framework and practical uses of the teaching materials. Trial lessons and seminars with the participation of editors may help a better understanding a particular textbook.

Currently, EAP is a course offered among freshmen in colleges in China. For those who have never been involved in academic English before, the genres of the articles, the academic vocabularies, complex sentence structures and exercises seem strange and difficult to them and it is likely that they soon lose interest and confidence during the learning process. It is suggested that teachers select what is appropriate and even tailor the materials according to their students' academic proficiency to ensure that the information input agrees with the ' $i+1$ ' theory, not too difficult for the learners to understand nor too simple for the acquisition of new knowledge. Materials closely related to learners' needs and proficiency helps the students, through cooperation with teachers, materials and their peers, achieve knowledge construction and maintain a healthy development of learning environment.

Another task that the teachers need to accomplish is to encourage effective interaction among students, textbook and the teacher in classroom activities, homework design and curriculum evaluation. The learning of difficult courses as EAP requires more than lecture study in classroom. Learners need more opportunities to understand, practice and reflect on the learning materials. Teachers, who serve as the guide of learning should encourage self learning, peer learning and review and help extend these learning activities outside of the classroom. Changes should also be made to the evaluation of learning result. Compared with the traditional terminative evaluation which determines students' proficiency by the final exam only, the formative assessment that highlights the learning process and students' participation scientifically evaluates the interest, attitude, learning ability, cooperation, learning strategy, intercultural awareness, etc. Strong supportive evidence is the research conducted by Zhou and Qin (2005) which discovered that formative assessment triggered students' learning motivation and interest. Through peer assessment and self assessment, students achieved better command of textbook knowledge and language skills and were able to reflect on their learning method and result and accordingly improved their ability of recognition and metacognition.

\subsubsection{Textbook}

The course EAP aims to develop learners' adaptive ability to academic context. Accordingly, the topics and materials selected for EAP textbook should be different from those for General English learning. Instead of adopting topics on daily life such as friendship, honesty, job and parenting, etc, EAP textbook is expected to cover more academic topics in specialties like business, computer, environment, pharmacy, technology, etc. On top of that, materials selected should serve as models of academic texts which the learners may come across in their future study or job, for example lectures, presentations, journal papers, conference articles, and so on.

EAP was firstly designed in English speaking countries to prepare the students for the college study in those countries. The EAP textbooks designed abroad offer lengthy introduction to skills and principles of writing academic papers in the early units, for college students in these countries are required to write term papers and accomplish academic projects and from the first semester. However, in China where students won't start writing academic paper until their last year in college, such content turns to be irrelevant and boring for freshmen. As a result, a lot of Chinese students lose interest of learning EAP at the beginning as they have to spend a lot of time learning skills that they consider as 'difficult' and 'useless' (something that they won't need until two or three years later and when the time comes, what learned is already forgotten). To maintain the motivation of learning this course, it is expected that EAP teaching materials (especially the first several units) used in Chinese context relate the materials closely to the learners' needs and are in line with their language proficiency. As is mentioned at the beginning of this article, what Chinese students want to gain from EAP course is the ability to understand and exchange information of a specialty, the ability to read and search for the literatures they need for their major, and the ability to understand a lecture of a particular field and the ability to interpret and demonstrate the 
academic results, etc. Writing academic paper, which requires higher language proficiency (in terms of sentence structure and research experience) is not their urgent concern. A good idea to arrange the materials is to assign the first several units to skills such as giving academic presentation, taking notes, participating in discussions, identifying the organization of an essay, writing summary, etc. Then, when the students have gained a sound command of the basic syntactic and discourse patterns of academic texts, content as demanding as writing research paper can be followed as to prepare them for the graduation thesis or future research (if there are any who will take part in research work).

The second consideration of choosing materials for non-native learners goes to language. Concerns should be given to the match of the difficulty of the materials (choice of vocabulary, sentence structure and exercises) with the learners' language proficiency. Take the Oxford EAP, for example, in the listening section of unit 6 , there is a listening section introducing photosynthesis, with so many difficult words such as chlorophyll, glucose, primary production, phosphorus, biomass, and kelp beds, etc, which soon kills the interest and patience of the freshmen. Such exercises, when used in Chinese context, should be revised and tailed beforehand. It might be better if a list of new words is listed and a brief introduction of background information is introduced first. The best solution, of course, is to choose materials with less difficult (and rarely used) vocabulary.

It is always believed that materials selected from real context with a certain communicative task can well meet the need of the learners for future communication in life. For example, if one unit focuses on the introduction of presentation skills, the materials provided could be the real situation of a student doing presentation in the class. The learners could comment on the given sample from the topic, content, language, and manner, etc with the skills they learn from the class and hence better understand the academic objectives and internalize what has been learned. Moreover, the creation of a learning environment that encourages effective interactions between teacher, learners and the materials is equally important. What should be noticed is that exercises that design pair work or group work to achieve such purposes only work when the input materials are able to trigger the willingness and ability to produce.

In this information age, a textbook that is merely made up of paper materials can hardly motivate learning interest and cooperation. On the contrary, one that makes full use of language, picture, audio and visual communications reinforces complements and helps understanding and furthers the memory of information. An EAP textbook that aims to build meaning construction and real communicative context, should select materials of diversified models. And the materials should be arranged from easy to difficult in a way that the gap shouldn't be huge which may lead to low efficiency of knowledge construction as the learners cannot connect the new information with their previous experience. Nor should the materials be too simple for the learners as they may lose interest if they find the new information overlapping with what they have already known.

\subsubsection{Extension of Textbook Learning in Virtual Learning Community}

Due to the limited time in EAP classroom learning (80-90 minutes per week) in China, a textbook cannot be fully made use of if the learning is not successfully extended to outside of the classroom. Take my university for example; we can barely finish 6 units (out of 12) of the textbook in one academic year, leaving half of the important topics and skills untouched. Even for these 6 units, the teachers have to delete a lot of content and exercises planned in the textbook. Many students complain that they only get a glimpse of what EAP is like when the course ends. It is quite necessary for them to finish the learning of the whole textbook so as to get a systematic command of the general skills needed for future academic study. However, this is not an easy task. Tang (1999) in his research discovered that Chinese students prefer competitive learning. Competitive learners put individual achievements in the first place. They always seek feedback or help from the most knowledgeable person (for example, teacher), and are unwilling to cooperate. However, in the virtual online forum, competitive learners are actively involved in discussion because this is the major source of information and feedback. For freshmen who haven't formed automatic learning habit, supervision and help from teachers and peer students are needed to further the exercises that are left over in classroom learning. In this netilizational era, online learning community brings the learners a feeling of being accepted, cared and respected and hence becomes an effective way of enhancing learners' participation by providing a good environment for cooperation and knowledge construction. (Arlan \& Sahin-kizil, 2010). In the virtual learning community, there are interactions between teachers, learners and textbook, peer reviews, exchanged opinions and social meaning construction through discussion, criticism and debate. The establishment of a virtual learning community extends the use of teaching materials in classroom and enhances the interactive connection among teachers, learners and the textbook. For EAP learning, it is important that a virtual learning community (whether on a website, qq, weibo or wechat) is established to optimize the learning environment and achieve effective interactions among the factors in it. 


\section{Conclusion}

As the educational globalization furthers, college students in China are exposed to various opportunities to deal with English language in different academic disciplines. In response to the growing need for learning academic English, EAP becomes a course widely implemented in universities in China. However, the teaching and learning feedback do not seem to be satisfactory. One of the main reasons is the lack of localized textbook. Despite of the urgent demand, there are few EAP textbooks designed (either at home or abroad) to cater to the need of overall (listening, speaking, reading and writing) development of academic skills. The adoption of textbooks designed by experienced publishers abroad brings up a problem of mismatch between textbook objectives and learners' need and language proficiency due to the editors' lack of understanding of learners' background. Also plays a role is teachers' lack of understanding of the teaching material. To many teachers, EAP is a new field and their lack of expertise in using the materials may lead to poor learning results. The previous researches on textbooks though successfully transferred their focus from linguistic skills to the learners' need and interest, did not pay enough attention to the interrelations between the influential factors in EAP learning process Eco-education theory highlights the interconnection of all ecological factors in a learning environment. Viewed from eco-education theory, the successful construction and implementation of an EAP textbook requires a balanced interaction between learners, teachers, editors, researchers and the teaching materials, etc. Before construction of the textbook, researches and investigations need to be carried out on consumers' (teachers and learners) needs of the course. Editors should base their work on a sound theoretic framework and the demands and problems in real teaching and learning context. Teachers are expected to have a profound understanding of the use of the materials as well as the theoretical basis behind. Interactions between teachers and students should always be encouraged inside and outside of the classroom. An effective option to extend limited classroom learning to outside cooperative learning is to establish a virtual learning community by making use of the popular communicative means among the youth. The selected teaching materials should not only be able to satisfy the overall English competence for academic disciplines but more importantly, cater to the interest and proficiency of local learners. The adoption of eco-education theory in EAP textbook construction brings us a realization that factors in a learning environment do not work alone and it is the interconnection that we need to consider to ensure a localized implementation of the textbook in a particular cultural context.

\section{References}

Arlan, R. S., \& Sahin-kizil, A. (2010). How Can the Use of Blog Software Facilitate the Writing Process of English Language Learners? Commuter Assisted Language Learning, 3, 183-192. https://doi.org/10.1080/09588221.2010.486575

Breen, M. P., \& Cadlin, C. N. (1987). Which Materials? A Consumer's and Designer's Guide. In L. E. Sheldon (Ed.), ELT Text-books and Materials: Problems in Education and Development (pp. 13-28). London: Modern English Publications in association with the British Council.

Cai, J. (2014). A Subversive Concept and Approach for Foreign Language Teaching-Research on the Difference between EAP and General English. Foreign Language Learning Theory and Practice, 2, 1-7

Cai, J. (2011). Research on the Compiling Concept of College English Textbooks at a Turning point Period. Foreign Language Research, 5, 5-10

Cunningswoth, A. (1984). Evaluating and Selecting EFL Teaching Materials. Heinemann Educational Books Ltd: London.

Edward de Chazal \& Sam, M. (2012). Oxford EAP-A course in English for Academic Purposes. Oxford: Oxford University Press.

Fernando, A., Genoveva, L., Daiel, M., \& Jose, M. V. (2005). An Instructional Model for Web-based E-learning Education with a Blended Learning Process Approach. British Journal of Educational Technology, 2, 217-235

Gremin, L. A. (1976). Public Education. Newyork: Basic Books.

Hutchinson, T., \& Waters, A. (1987). Englsih for Specific Purpose. Cambridge: Cambridge University Press. https://doi.org/10.1017/CBO9780511733031

Hyland, K. (2006). English for Academic Purposes: An Advanced Resource Book. London and New York: Routledge ,

Liu, H. (2015). Needs Analysis on EAP Reading Abroad and the Inspiration to the EAP reading in China. Foreign Language Research, 2, 56-59 
Mcdonough, J., \& Shaw, C. (1993). Materials and Methods in ELT. Cambridge and Mass: Blackwell.

Qin, D. (2003). Scientific English. Xi An: Xidian University Press.

Tang, S. (1999). Cooperation or Competition: A Comparison of U.S and Chinese College Students. The Journal of Psychology, 133, 413-423. https://doi.org/10.1080/00223989909599752

Shu, D., \& Anlin. (2014). Special Features and Trends of Recently-published English-for Academic-Purposes Textbooks. Foreign Language Learning Theory and Practice, 4, 9-18.

Shu, D. F. (2004). Innovation on Foreign Language Teaching: Problems and Counter Measures. Shanghai: Shanghai Foreign Language Education Press.

Sun, Y. B., Feng, J. (2014). A review of the Researches on EAP inRecent Years. Journal of Kunming University of Science and Technology, 6, 89-96

Van Lier, L. (1997). Approaches to Observation in Classroom Research-Observation from an Ecological Perspective. TESOL Quarterly, 4,783-787. https://doi.org/10.2307/3587762

Yang, H. Z., Wang, Y. (2015). New Century College English: Listening and Note taking Skills. Shanghai: Shanghai Foreign Language Education Press

Yang, M., \& Yang, X. F. (2007). The Reading Course of English Science and Technology. Bei Jing: Foreign Language Teaching and Research Press.

Yang, Y. Y.. (2016). Comprehensive Courses for General Academic English. Bei Jing: National Defense Industry Press.

Yuli, L. J., \& Chen, Y. G. (2015). English Writing for Academic Purposes. Bei Jing: Qing Hua University Press.

Zhao, Y., Zheng, \& S. T. (2006). Theoretical Analysis to the Evaluation System on English Textbooks Abroad-Inspirations to Chinese English Textbooks. Foreign Language Teaching, 5, 39-45.

Zhou, P. D., \& Qin, X. B. (2005). Application of Formative Assessment in Web-based College English Teaching. Computer-assisted Foreign Language Education, 10, 9-14.

\section{Copyrights}

Copyright for this article is retained by the author(s), with first publication rights granted to the journal.

This is an open-access article distributed under the terms and conditions of the Creative Commons Attribution license (http://creativecommons.org/licenses/by/4.0/). 